\title{
A recuperabilidade em Objetos de Aprendizagem de Línguas: descritores em repositórios digitais
}

\section{The recoverability in Learning Objects of Languages: describers in digital repositories}

\begin{abstract}
Alan Ricardo Costa* Vanessa Ribas Fialho**

Resumo: A finalidade da presente pesquisa é discutir a característica da recuperabilidade e sua importância para Objetos de Aprendizagem (OAs) e Objetos de Aprendizagem de Línguas (OALs), sobretudo no que diz respeito à presença de descritores em repositórios. Tal discussão se dá tendo como base uma investigação de cunho exploratório efetuada pelo grupo de pesquisadores responsáveis pelo repositório virtual de recursos didáticos para o ensino de Espanhol como Língua Estrangeira (E/LE) Acción E/LE, com vistas a destacar o papel de descritores que propiciem uma recuperabilidade pedagógica. Os resultados indicam que seis dos sete repositórios averiguados apresentam descritores pedagógicos, como "nível do objeto (básico, intermediário ou avançado)", por exemplo, que podem contribuir para a construção de uma lista de descritores para o Repositório Acción E/LE. Conclui-se que os atuais repositórios de OAs, apesar de passíveis de melhorias quanto ao uso e a organização de descritores pedagógicos, podem servir como referência para o aumento da recuperabilidade de repositórios digitais de OALs.
\end{abstract}

Palavras-Chave: Objetos de Aprendizagem de Línguas; Recuperabilidade; Descritores.

Abstract: The aim of the present research is to discuss the characteristics of recoverability and its importance for Learning Objects (LOs) and Learning Objects of Languages (LOLs), mainly regarding the presence of describers in repositories. Such discussion occurs having as basis an investigation of exploratory aim carried out by the group of researchers responsible for the virtual repository of didactic resources for the teaching of Spanish as Foreign Language (S/FL) Acción E/LE, attempting to emphasize the describers' role which enables pedagogical recoverability. The results show that six of the seven analyzed repositories present pedagogical describers, such as "object level (basic, intermediary or advanced)", for example, that can contribute for the construction of a list of describers for Los Acción $\mathrm{S} / \mathrm{FL}$. One may conclude that the current LOs repositories, despite their possible improvements related to the use and the organization of pedagogical describers, may serve as reference for the increase of recoverability of digital LOLs repositories.

Keywords: Learning Objects of Languages; Recoverability; Describers.

*Acadêmico do curso de licenciatura em Letras - Espanhol e literaturas da língua espanhola, da Universidade Federal de Santa Maria (UFSM). Bolsista de Iniciação Científica no projeto "A produção de OAs para o ensino de E/LE", com financiamento institucional do Conselho Nacional de Desenvolvimento Científico e Tecnológico (CNPq). E-mail: alan.dan.ricardo@gmail.com.

${ }^{* *}$ Professora Adjunta do Departamento de Letras Estrangeiras Modernas (DLEM), da Universidade Federal de Santa Maria (UFSM). Doutora em Linguística Aplicada pela Universidade Católica de Pelotas (UCPel) e coordenadora do projeto de pesquisa “A produção de OAs para o ensino de E/LE”. É responsável pela coordenação do repositório virtual de recursos didáticos Acción E/LE, apresentado ao longo do artigo. E-mail: vanessafialho@gmail.com. 


\section{Primeiras considerações}

A área de ensino de línguas vem sendo constantemente enriquecida por novos debates teóricos, bem como novas Tecnologias de Informação e Comunicação (TICs) que ajudam professores e alunos nesse árduo e longo caminho a se percorrer entre a língua materna e a Língua Estrangeira (doravante LE). Um dos debates que vem acontecendo com bastante frequência na academia diz respeito ao uso de Objetos de Aprendizagem (OAs, de agora em diante), que se destacam como um importante recurso educacional, pois são capazes de aferir um caráter dinâmico, interativo, flexível e motivador ao processo educativo (SILVA; FAGUNDES; BASSO, 2008).

Quanto aos OAs destinados ao ensino de línguas (ver, por exemplo, LEFFA, 2006a; TAVARES, 2007; GARCIA; LEFFA, 2010; GARCIA, 2011, VETROMILLE-CASTRO et. al., 2012), é importante destacar que estes possuem definições bastante amplas, que variam desde "qualquer objeto" até "objeto digital com fim educacional" (LEFFA, 2006a; McGREAL, 2004). Esta última concepção - objeto digital com fim educacional - vinha sendo dominante na área de ensino de línguas (LEFFA, 2006a), sendo aprimorada posteriormente por outros autores, como Garcia (2011), que contribuiu no sentido de apontar que um objeto digital que possui 'fim educacional' é um objeto digital cujo planejamento e apresentação do conteúdo deve estar embasado em uma teoria de aprendizagem.

Contudo, contribuindo ainda mais para o aprimoramento de uma concepção de OA específica para o ensino de línguas, Vetromille-Castro et. al. (2012) propuseram o conceito de Objeto de Aprendizagem de Línguas (OAL), que aponta a abordagem comunicativa como o suporte teórico que, até então, nos comentários de Garcia (2011), ainda não estava especificado. Em suma, a principal distinção entre OAs e OALs diz respeito ao enfoque dado ao Ensino Comunicativo de Línguas ${ }^{1}$ (CLT), tendo como norte o desenvolvimento das competências comunicativas dos aprendizes. Um OAL se define por isso.

Esta proposta de concepção formulada por Vetromille-Castro et. al. (2012), cumpre esclarecer, é compartilhada pelos participantes do projeto de pesquisa $A$ produção de Oas para

\footnotetext{
${ }^{1}$ Resumidamente, a abordagem comunicativa prima pela ênfase no sentido, na comunicação e na interação entre os falantes. Da mesma forma que Vetromille-Castro et. al. (2012), optamos por utilizar a sigla CLT, referente ao termo em inglês Communicative Language Teaching, por ser amplamente conhecido e referido na área de aprendizagem de línguas.
} 
o ensino de $E / L E^{2}$. Tal projeto se ocupa de investigar, avaliar e produzir OALs específicos para o ensino de Espanhol como Língua Estrangeira (E/LE). Os motivos que levam esta concepção a ser considerada até então a mais promissora na opinião do grupo de pesquisa são vários. Por exemplo:

(1) Por apoiar-se teoricamente na abordagem comunicativa, a concepção de OAL não se restringe à neutralidade teórica. Seu suporte teórico, CLT, já há alguns anos mantêm-se em constante ascensão na área da Linguística Aplicada (VETROMILLE-CASTRO et.al., 2012).

(2) Ainda por partir do enfoque comunicativo, entende-se que um OAL precisa manter o foco nas necessidades de comunicação do aprendiz (aluno) e, também, deve ter como objetivo facilitar a integração das competências gramatical, sociolinguística e estratégica (VETROMILLE-CASTRO et. al., 2012).

No entanto, vale destacar que, para o presente trabalho, o motivo principal é justamente o fato de que, na revisão de literatura, a pesquisa de Vetromille-Castro et. al. (2012) é a que, talvez, aponte com maior veemência a importância de trazer à luz discussões mais voltadas para o viés pedagógico do que para o viés técnico dos OAs e dos OALs. Um exemplo dessa questão é o uso de descritores para armazenar OAs e/ou OALs em repositórios digitais. A característica recuperabilidade, que diz respeito à forma de localização e recuperação de determinado OA ou OALs a partir do acesso ao objeto via descritores, nos dias atuais, está contemplando mais aqueles descritores voltados a informações técnicas do objeto, como "formato do objeto"? Ou estariam contemplando, com o devido e necessário destaque, descritores mais pedagógicos, como "nível (básico, intermediário, avançado)" ou "habilidade comunicativa trabalhada (leitura, escrita, compreensão oral e produção oral)"? É o que se pretende descobrir.

Tendo em vista as considerações precedentes, este trabalho tem por objetivo discutir a característica recuperabilidade e sua importância para OALs, sobretudo no que diz respeito à presença de descritores em repositórios digitais. Pretende-se contribuir com as discussões incitadas por Vetromille-Castro et. al. (2012) quanto ao uso de descritores pedagógicos, visando buscar em repositórios de OAs possíveis descritores que contemplem o lado pedagógico do referido recurso.

Neste contexto, apresentamos esta pesquisa, que está divida da seguinte maneira. Primeiramente é feita uma breve discussão sobre o conceito de OAL, suas principais

\footnotetext{
2 Projeto de pesquisa em andamento oficial desde abril de 2012 e registrado pelo número 031354 no Gabinete de Projetos do Centro de Artes e Letras (GAP/CAL), da Universidade Federal de Santa Maria (UFSM).
} 
características e, dentre elas, a característica de recuperabilidade. Na sequência são apresentadas colocações quanto ao armazenamento dos OALs em repositórios digitais e a importância dos descritores, enquanto que, logo em seguida, são apresentados alguns exemplos de repositórios de OAs. Posteriormente é apresentada a metodologia da pesquisa e, depois, os resultados e as devidas discussões. Por fim, são apresentadas as considerações finais.

\section{Objeto de Aprendizagem de Línguas}

Um OA, entendido até então como um objeto digital com fim educacional, poderia ser "qualquer arquivo digital (texto, imagem ou vídeo), desde que usado para facilitar e promover a aprendizagem" (LEFFA, 2006a, p.7). A partir daí, um OA se delimitava a partir das suas 4 características principais, a saber:

1) Reusabilidade: diz respeito à possibilidade de (re)utilização de um OA em outro contexto a partir da capacidade de modificação desse objeto.

2) Interoperabilidade: é a habilidade de transferir e utilizar informações de maneira uniforme e eficiente entre várias organizações e sistemas de informação (GARCIA, 2011), seja em diferentes máquinas, em diferentes navegadores, etc.

3) Granularidade: diz respeito à capacidade de identificar e intervir na forma e no tamanho do OA (ou de suas partes), possibilitando que estas possam ser encaixadas umas às outras, permitindo, desse modo, que o todo inclusive se encaixe com outro todo (outro OA).

4) Recuperabilidade: diz respeito à forma de localização e recuperação de determinado OA a partir do acesso ao objeto.

Com a atual proposta de OAL, feita por Vetromille-Castro et. al. (2012), no entanto, dois 'problemas' referentes à concepção de OA para a área de ensino de línguas foram possivelmente resolvidos. O primeiro deles é a questão da neutralidade teórica e o segundo é a tendência à valorização do lado técnico do $\mathrm{OA}$, muitas vezes deixando de lado a parte pedagógica.

A neutralidade teórica se define como a noção de que o uso desses objetos não precisa estar necessariamente atrelado a uma determinada teoria de aprendizagem, e é sumariamente rejeitada em muitos segmentos da academia (LEFFA, 2006a). A neutralidade teórica é rebatida por vários autores, como Wiley (2000), Vetromille-Castro et. al. (2012) e, ainda, Castro e Sedrez (2011, p.1), que questionam: “Ora, qual é o propósito de um Objeto de Aprendizagem se não há aprendizagem propriamente dita, ou se ela é seriamente comprometida pela falta de 
teorias que permitam sua ocorrência?". O impasse na neutralidade teórica pode ser considerado solucionado com a proposta de OAL de Vetromille-Castro et. al. (2012), que tem como embasamento teórico os princípios comunicativos ${ }^{3}$ propostos por Canale e Swain (1980). Portanto, os OALs "respondem à crítica de serem teoricamente neutros, pois para um OA ser considerado OAL, ele deve ser obrigatoriamente baseado em princípios do Ensino Comunicativo de Línguas (CLT)” (CASTRO; SEDREZ, 2011, p.1).

Já o problema da valorização dos aspectos técnicos do objeto é evidenciado pelas concepções de interoperabilidade, granularidade, reusabilidade e recuperabilidade. Estas concepções por vezes podem esquecer ou descuidar-se daquele que deveria ser o componente fundamental do objeto: a aprendizagem (VETROMILLE-CASTRO et. al. 2012). Um exemplo de característica que ainda nos dias atuais pode ser entendida como demasiadamente técnica é a recuperabilidade. Esta, segundo Vetromille-Castro et. al.(2012)

volta a olhar para OAs em repositórios. No momento em que o usuário quiser um OA para compor sua unidade de ensino e/ou de aprendizagem, irá buscar em um repositório. $\mathrm{O} \mathrm{OA}$ deverá ser facilmente localizado pelo usuário através de metadados. Esses funcionam como etiquetas que descrevem o OA [...] e devem ter sido elaborados com base em teorias que dêem conta da aprendizagem e do ensino, no nosso caso, de línguas. Para efetuar a busca, então, o usuário pode procurar por alguns metadados mais específicos, a fim de localizar o que ele precisa. Até o momento, ouve-se falar de metadados técnicos [...], mas não de metadados pedagógicos, o que, na nossa ótica, negligencia o elemento principal do OA - a aprendizagem (VETROMILLECASTRO et. al. 2012, p.245).

Assim, a proposta dos OALs de Vetromille-Castro et. al. (2012), além de tentar sobrepor a barreira da neutralidade teórica, tenta, também tirar o holofote de questões mais técnicas e dar destaque para questões mais pedagógicas dos OAs.

\section{Repositórios digitais e a importância dos descritores}

Inicialmente, a concepção de OA como objeto digital não era unânime. Este ponto vinha sendo colocado em debate desde o surgimento das primeiras concepções de OA. Como exemplo, vale citar a apresentação da definição do Learning Technology Standards Committee

\footnotetext{
${ }^{3}$ Duas das releituras dos principios comunicativos de Canale e Swain (1980), feitas por Vetromille-Castro et. al. (2012, p.250) para os OALs, são: (1) O OAL deve dar atenção à forma da LE em situações de comunicação, levando o aluno do implícito ao explícito no uso da língua; (2) O OAL deve possuir aspectos sócio-linguísticoculturais da LE e dos próprios aprendizes, para facilitar a aprendizagem da língua.
} 
(LTSC), do Institute of Electrical and Electronics Engineers (IEEE), um dos primeiros a expor uma definição para OA, que podia ou não ser digital (LTSC, 2006).

Com o passar do tempo, tal discussão foi perdendo fôlego. Publicações de novas pesquisas referentes ao tema permitiram que estudiosos vislumbrassem certa tendência entre os acadêmicos: um grande número de autores optou por uma definição de OA como objeto preferencialmente (ou necessariamente) digital: Wiley (2000), Schwarzelmüller e Ornellas (2006), Leffa (2006a), South e Monson (2007), Gallo e Pinto (2010), Garcia (2011), Costa e Fialho (2012), Vetromille-Castro et. al. (2012) e muitos outros. A explicação para tal tendência reside, sobretudo, no fato de que, em mídia digital, há uma potencialização das quatro principais características de um OA, já apontadas anteriormente. Quanto à característica da recuperabilidade, escopo do presente trabalho, esta foi otimizada justamente pela utilização de repositórios digitais para o armazenamento e catalogação dos objetos.

Vale resgatar aqui, para dar continuidade às discussões, os apontamentos de Gama (2007, p.64): "Para reusar um objeto de aprendizagem é necessário ter acesso a ele com certa facilidade, poder encontrá-lo e recuperá-lo". Para tanto, é importante que alguns aspectos sejam considerados. Por exemplo, o OA deve estar devidamente disponível em um repositório (GAMA, 2007). Se tal repositório está em meio digital, seu acesso é, evidentemente, muito mais fácil, dinâmico, rápido, seu alcance é estendido a todo o território alcançado pela rede mundial de computadores e seu conteúdo pode ser entendido como facilmente recuperável, apenas para citar os benefícios mais visíveis.

A principal qualidade da Internet, contudo, pode ser entendida também como seu maior defeito. Ao imaginarmos a Internet como a maior biblioteca de OAs já criada, e sempre em constante atualização, como um professor conseguiria orientar-se por ela buscando o OA específico que ele deseja? Conseguiria apenas a partir de uma boa recuperabilidade dos repositórios digitais que visita. Entra aí, então, a importância dos descritores, pois, dependendo de como esse armazenamento de OAs é feito em um repositório digital, e do quão fácil será a recuperação de um OA, será determinado, possivelmente, o maior número de acessos a um OA ou a um repositório de OAs.

Conforme menciona Leffa (2006a), um OA deve também ter seu acesso facilitado, de maneira que o usuário obtenha exatamente aquilo que deseja do modo mais rápido possível. Esse acesso ao objeto desejado é feito através do que na área se convencionou chamar de metadados ("metadata", em inglês). 
O metadado de um objeto educacional descreve características relevantes que são utilizadas para sua catalogação em repositórios de objetos educacionais reusáveis, podendo ser recuperados posteriormente através de sistemas de busca ou utilizados através de learning management systems (LMS) para compor unidades de aprendizagem (TAROUCO; FABRE; TAMUSIUNAS, 2003, p.2).

“Os metadados (descrição dos conteúdos) vão permitir que os sistemas efetuem operações automáticas sobre um conjunto importante de recursos (classificação, seleção, busca, recuperação...)" (GAMA, 2007, p.67).

Basicamente, então, trata-se de um sistema de catalogação, como se usa numa biblioteca, em que a ficha do livro informa não apenas sua localização nas prateleiras, mas também fornece descritores, como o título, nome do autor, número de ISBN ou até palavras-chave, permitindo, às vezes, a busca por qualquer um desses descritores (LEFFA, 2006a, p.26).

Não custa repetir que o que se entende por descritores entre pesquisadores de OAs são precisamente os aspectos designados para descrever dado objeto e, de tal modo, aumentar seu nível de recuperabilidade, a partir da facilitação de sua localização e de seu acesso por parte de possíveis usuários. Gama (2007) aponta que um objeto devidamente catalogado facilita a busca e torna seu acesso rápido e imediato, elevando o grau de satisfação do usuário.

De acordo com Gama (2007), um dos melhores exemplos de descrição de OAs é proposto pelo site Dublin Core Metadata Initiative ${ }^{4}$, que é aplicável a qualquer tipo de documento digital e contém quinze categorias de descritores: (1) Título; (2) Autor ou criador; (3) Assuntos e palavras chave; (4) Descrição; (5) Publicador; (6) Outros contribuintes; (7) Data; (8) Tipo de recurso; (9) Formato; (10) Identificador do recurso; (11) Fonte; (12) Idioma; (13) Relação; (14) Cobertura e (15) Direitos autorais.

Segundo Leffa (2006a), entre os descritores que têm sido incluídos para descrever os OAs também se destacam aqueles listados por Clark e Rosset (2002), como pode ser observado na tabela a seguir:

Tabela 1 - Descritores propostos por Clark e Rossett (2002).

\section{Descritor}

Alternativas de descrição

Título do objeto

Língua usada

Descrição resumida

\footnotetext{
${ }^{4}$ Disponível em http://dublincore.org/. Acesso em 10 de agosto de 2012.
} 


\begin{tabular}{|c|c|}
\hline Palavras-chave & \\
\hline $\begin{array}{c}\text { Nome de quem contribuiu } \\
\text { Papel de quem contribuiu }\end{array}$ & Autor; Designer educacional; Editor; etc. \\
\hline Estrutura do objeto & $\begin{array}{c}\text { Atômico; Coleção; Hierárquico; Linear; Ramificado; Misto; } \\
\text { etc. }\end{array}$ \\
\hline Tipo de interatividade & Ativo; Expositivo; Indefinido; Misto \\
\hline $\begin{array}{c}\text { Nível de interatividade } \\
\text { Papel do usuário final }\end{array}$ & $\begin{array}{c}\text { Auto-avaliação; Definição de problema; Diagrama; } \\
\text { Exercício; Experimento; Figura; Gráfico; Índice; } \\
\text { Questionário; Simulação; Slide; Tabela; Teste; Texto } \\
\text { Idade sugerida para } \\
\text { execução da atividade }\end{array}$ \\
\hline Contexto sugerido & Aprendiz; Autor; Gerente; Professor; \\
\hline Dificuldade & $\begin{array}{c}\text { Educação básica; Educação continuada; Educação média; } \\
\text { Educação universitária; Escola técnica; Formação } \\
\text { profissional; etc. }\end{array}$ \\
\hline
\end{tabular}

Os dois modelos de grade de descritores apresentados anteriormente são entendidos como modelos gerais, ou seja, são descritores que cabem para descrever OAs em geral. Ademais destes, conforme aponta Leffa (2006a), há de se considerar descritores específicos para a aprendizagem em questão, para não contemplar apenas o lado técnico do OA, deixando em segundo plano o aspecto pedagógico. Em outras palavras, no caso do ensino de LEs, por exemplo, juntamente com os descritores gerais, devem ser considerados os descritores específicos para o viés pedagógico. Assim, Leffa (2006a) atenta para o fato de que uma catalogação de OAs específicos de ensino de línguas deveria, provavelmente, incluir, entre tantos outros descritores, os seguintes: nível de adiantamento (básico, intermediário, avançado), habilidade (fala, escuta, leitura, escrita), tipo de atividade (diálogo interativo, cloze, jogo didático, etc.), campo semântico (cores, peças do vestuário, meios de transporte, etc.), atos de fala (promessa, negação, pedido de desculpa, etc.) (LEFFA, 2006a, p.14). 


\section{Exemplos de repositórios de OAs ${ }^{5}$}

Leffa (2006b), visando contribuir com a demanda de produção e uso de OAs específicos para o ensino de línguas em âmbito acadêmico, concretizou a construção de um repositório de OAs. Trata-se do repositório ELO - Ensino de Línguas Online, que possui também um sistema de autoria para a produção de materiais digitais voltados especialmente para o ensino de línguas (ou seja, OAs de línguas).

Com o ELO você pode criar diferentes tipos de atividades, incluindo leitura de texto com dicionário acoplado, fazer perguntas e avaliar as respostas do aluno, dar feedback progressivo para cada resposta do aluno, correta ou não, além de outros tipos de atividade. ELO não exige instalação e não espalha arquivos pelo seu HD. Pode ser copiado diretamente para uma pasta (ELO, 2012).

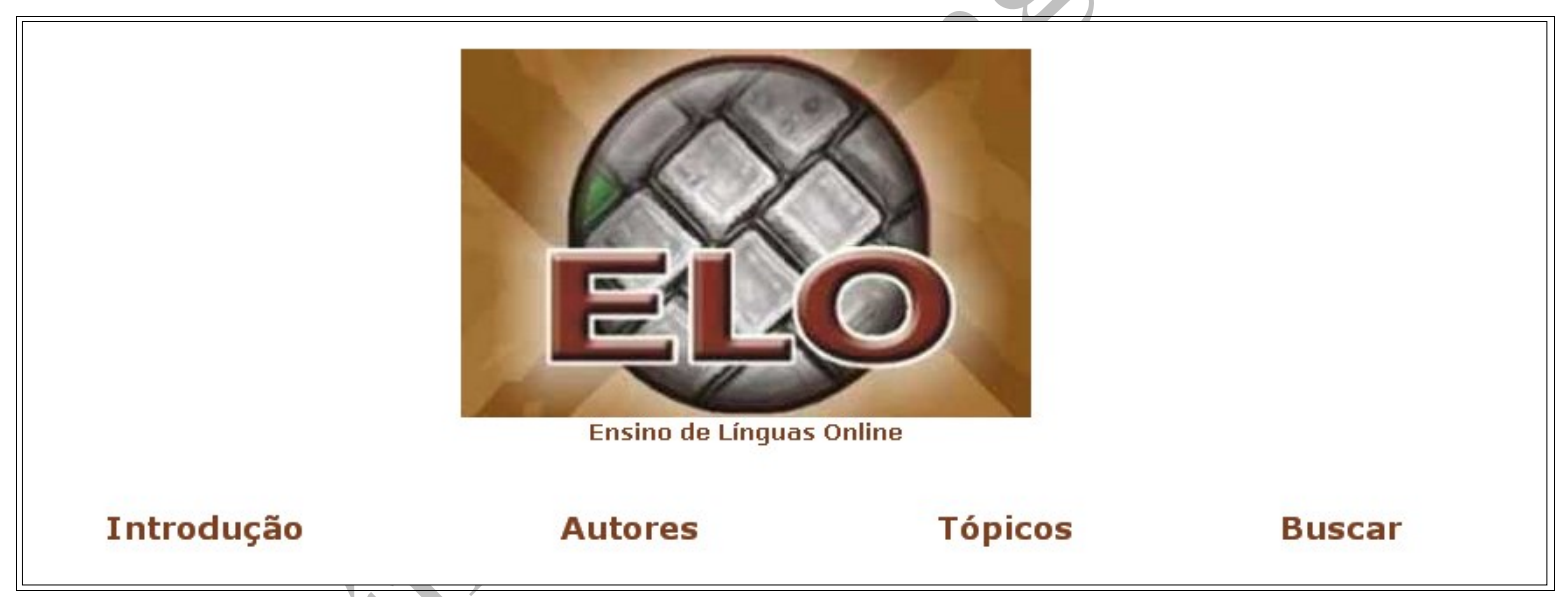

Imagem 1: Repositório ELO - Ensino de Línguas Online ${ }^{6}$.

O acesso ao acervo de dados do $E L O$ se dá de maneira equivalente ao uso de descritores, ainda que não de forma convencional. Como pode ser visto na imagem anterior, o visitante se depara com algumas opções de navegação nas diferentes seções do site, como as seguintes:

- Autores. Os vários professores de língua que colaboraram com o ELO por meio da idealização e desenvolvimento de OAs para o ensino de línguas são divididos aqui por ordem alfabética: de $\mathrm{A}$ à $\mathrm{D}$, de $\mathrm{E}$ à $\mathrm{M}$ e de $\mathrm{N}$ à $\mathrm{Z}$.

- Tópicos. Nessa seção, o visitante escolhe o idioma com o qual o OA vai trabalhar. Pode ser Espanhol, Inglês, Português ou Outros (Latim ou outros tópicos).

\footnotetext{
${ }^{5}$ Vamos considerar a partir de agora que um repositório é, resumidamente, um ambiente que armazena e facilita a recuperação de um OA. Quando entendemos um OA como um objeto digital com fim educacional, por conseguinte entendemos que o site que aloca vários OAs é um repositório digital de OAs. Ainda não efetuamos pesquisas referentes à classificação de sites como sendo repositórios de OAs ou repositórios específicos de OALs.

${ }^{6}$ Para maiores informações sobre o ELO, visite: http://www.leffa.pro.br/elo/index.html.
} 
Estas seções e opções de navegação - descritores usados por Leffa - não deixam de atuar como descritores dos OAs, uma vez que o visitante se depara com a língua usada no OA, o autor do objeto, e posteriormente com outros descritores, como título, tipo de atividade, etc.

Além do repositório ELO é oportuno citar aqui o site Acción $E / L E^{7}$, repositório de recursos disponíveis gratuitamente na Internet e aptos a serem empregados como ferramentas mediadoras do processo de ensino-aprendizagem de E/LE, por professores (formados ou em formação) e demais interessados no estudo da referida LE. O repositório Acción $E / L E$ atualmente é coordenado pelos pesquisadores atuantes no projeto de pesquisa $A$ produção de OAs para o ensino de E/LE, já citado em linhas anteriores.

Resumidamente, tal projeto de pesquisa visa contribuir com a comunidade acadêmica adepta ao uso de TICs, em geral, e OALs, especificamente, da seguinte maneira: pretende-se que o repositório Acción E/LE, em um futuro não muito distante, seja ampliado e aprimorado de modo a tornar-se um repositório de OALs com alta recuperabilidade. Portanto, a recuperabilidade de um OAL, com bons descritores, que facilitem o acesso dos professores a atividades de seu interesse e que contemplem o viés pedagógico necessário para auxiliar o docente em sua prática, é o grande desafio.

\section{Metodologia}

Tendo em vista o objetivo do presente trabalho, que é discutir a recuperabilidade dos OALs para o ensino de línguas a partir principalmente da importância dos descritores pedagógicos na facilitação do acesso e recuperação do objeto, apresentamos aqui a metodologia seguida pelos pesquisadores do projeto de pesquisa $A$ produção de OAs para o ensino de E/LE para a identificação de descritores próprios para o armazenamento de OALs de E/LE.

Basicamente entendemos que repositórios digitais de OAs tendem a ter descritores que orientem a busca de seus visitantes por objetos específicos. Cabe descobrir se estes descritores são todos técnicos (ou seja, como comentamos anteriormente, descritores gerais) ou se são específicos para o ensino de língua, em outras palavras, descritores pedagógicos. Isso porque entendemos que determinados descritores aplicados a repositórios de OAs podem ser úteis futuramente para a catalogação de OALs, em repositórios específicos, como se pretende que seja o Repositório Acción E/LE.

\footnotetext{
${ }^{7}$ Para maiores informações sobre o Acción E/LE, visite: www.ufsm.br/accionele.
} 
Destarte, foram selecionados justamente repositórios de $\mathrm{OAs}^{8}$ de espanhol, assim como o próprio Acción E/LE. Na verdade, este foi o ponto de partida para a seleção do corpus. Dentro do Acción E/LE há uma lista de sites que armazenam atividades online de língua espanhola. Trata-se da taxonomia Actividades online ${ }^{9}$, composta de 7 (sete) sites que compõe o corpus do presente estudo, a saber: (1) Ejercicios de español para extranjeros, (2) Actividades FORMESPA, (3) ELO - Ensino de Linguas Online, (4) Lecturas paso a paso de CVC, (5) Aveteca de CVC, (6) Autoactividades de español em hlrnet.com e (7) Más arriba: Spanish Language Exercises.

O processo metodológico seguido foi o de uma investigação de cunho exploratório nos supracitados sites de atividades online. A referida investigação exploratória tinha como princípios norteadores a investigação a forma de armazenamento e o nível de recuperabilidade dos repositórios.

A análise do armazenamento e da recuperabilidade, feita com base na revisão de literatura que aborda os descritores (LEFFA, 2006a; CLARK; ROSSET, 2002; GAMA, 2007), teve como critérios de investigação as seguintes questões:

a) Quais descritores são empregados pelos repositórios? E quais destes são descritores específicos (pedagógicos)?

b) Qual a média quantitativa de descritores empregados?

c) Como se dá o acesso aos objetos? De que maneira os descritores são expostos ao visitante do site? Os descritores estão expostos de maneira a facilitar o acesso ao OA/OAL?

d) Há o uso de descritores, tanto gerais quanto específicos, novos? Ou seja, há o uso de descritores (sobretudo aqueles que são pedagógicos)inéditos? Descritores ainda não aludidos na revisão de literatura?

\section{Resultados e discussão}

Apresentamos a seguir uma tabela com os descritores empregados por cada um dos repositórios investigados. Aqueles descritores considerados específicos para o processo de ensino/aprendizagem de línguas (descritores pedagógicos) também são expostos, em destaque.

Dentre os descritores apresentados, "Nome" pode ser considerado o descritor chave para a identificação e o armazenamento dos OAs.

\footnotetext{
${ }^{8}$ Neste momento, ainda não sabemos se esses objetos são OALs ou apenas exercícios ou atividades que poderiam compor um OAL.

${ }^{9}$ Disponível em http://w3.ufsm.br/accionele/actividades online.htm.
} 
Tabela 2 - Descritores utilizados pelos repositórios.

\begin{tabular}{|c|c|c|c|}
\hline & Repositório & Descritores $^{10}$ & Descritores pedagógicos \\
\hline 1 & $\begin{array}{l}\text { Ejercicios de español } \\
\text { para extranjeros }\end{array}$ & $\begin{array}{l}\text { Nombre; Fecha de } \\
\text { inserción. }\end{array}$ & $\begin{array}{c}\text { Tipo de ejercicios (Vocabulario, } \\
\text { Escucha, Gramática); Nivel } \\
\text { (Principiantes, Intermediarios, } \\
\text { Avanzado); Tipo de actividad } \\
\text { (Crucigrama, Juego de memoria, } \\
\text { etc.); }\end{array}$ \\
\hline 2 & $\begin{array}{l}\text { Actividades } \\
\text { FORMESPA }\end{array}$ & $\begin{array}{l}\text { Nome; Autor; Material } \\
\text { necesario; Duración. }\end{array}$ & $\begin{array}{c}\text { Nivel; Destinatarios; Objetivos } \\
\text { (Generales, Especificos y } \\
\text { Culturales); Procedimiento. }\end{array}$ \\
\hline 3 & $\begin{array}{l}\text { ELO - Ensino de } \\
\text { Linguas Online }\end{array}$ & $\begin{array}{l}\text { Nome; Autores (de A à } \\
\text { D, de E à M e de N à } \\
\text { Z); Tópicos (línguas: } \\
\text { Espanhol, Inglês, } \\
\text { Português ou Outros). }\end{array}$ & $\begin{array}{l}\text { atividade (Cloze, Eclipse, } \\
\text { Memória, etc.). }\end{array}$ \\
\hline 4 & $\begin{array}{l}\text { Lecturas paso a paso } \\
\text { de CVC }\end{array}$ & Nom & $\begin{array}{l}\text { Información sobre el texto }{ }^{11} ; \text { Nivel } \\
\text { (Inicial, Intermedio, Avanzado); } \\
\text { Grado de dificultad }(1,2,3,4 \text { e } 5) \\
\text { Información sobre la explotación } \\
\text { didáctica. }\end{array}$ \\
\hline 5 & Aveteca de CVC & $\begin{array}{l}\text { Nome; Tiempo de } \\
\text { realización estimado }\end{array}$ & $\begin{array}{c}\text { Nivel }{ }^{\mathbf{1 2}} \text {; Objetivo; Apartado; } \\
\text { Conocimientos previos; Sugerencias } \\
\text { de explotación; Nivel (Elemental, } \\
\text { Intermedio bajo, Intermedio alto, } \\
\text { Superior). }\end{array}$ \\
\hline 6 & $\begin{array}{l}\text { Autoactividades de } \\
\text { español em hlrnet.com }\end{array}$ & $\begin{array}{c}\text { Nome; Data de } \\
\text { publicação; Autor }{ }^{13} \text {. }\end{array}$ & $\begin{array}{c}\text { Categoría (Animales, Cine, Comida, } \\
\text { etc.). }\end{array}$ \\
\hline 7 & $\begin{array}{l}\text { Más arriba: Spanish } \\
\text { Language Exercises }\end{array}$ & $\begin{array}{l}\text { Nome/conteúdo } \\
\text { trabalhado }\end{array}$ & Nome/conteúdo trabalhado \\
\hline
\end{tabular}

Os descritores "Tempo de realização estimado", "Duração" e outros semelhantes não foram considerados pedagógicos porque, na concepção de OAL, podemos inferir que a duração do objeto é delimitada pelo uso pedagógico que o professor ou o aluno faz dele. Nesse viés, a característica da granularidade, que é o maior desafio dos teóricos da área (LEFFA, 2006a; VETROMILLE-CASTRO et. al. 2012) não tenderia a calcular o tamanho do objeto por sua duração. O OAL teria o tamanho necessário para cumprir seu fim comunicativo, seja ele qual

\footnotetext{
${ }^{10}$ Aqueles descritores que estavam sinalizados no próprio site, em espanhol, foram transcritos em itálico, enquanto que os demais, que não estavam "nomeados", ou estavam em português, não.

${ }^{11}$ O texto empregado na atividade. Trata-se, na verdade, de "Referências".

${ }^{12}$ Níveis de referencia A1-A2, B1-B2 e C1, com base no Plan curricular del Instituto Cervantes. Para maiores informações: http://cvc.cervantes.es/ensenanza/biblioteca ele/plan curricular/default.htm.

${ }^{13} \mathrm{Na}$ verdade, trata-se do perfil online da pessoa que publicou o objeto no site. Para a pesquisa, contudo, vamos considerar este descritor como sendo "Autor".
} 
for. Logo, o tamanho não poderia ser considerado por um tempo pré-determinado. Talvez sugerido, indicado, mas nunca pré-determinado.

Destes repositórios, o site Más arriba: Spanish Language Exercises é o que surpreende negativamente pela falta quase total de descritores. Apenas o nome das atividades está exposto, e demais informações podem aparecer ou não se o visitante entrar e testar as atividades por conta própria. Além de o site estar em sua maioria estruturado em inglês, inclusive a seção com atividades em espanhol, o único descritor utilizado para apresentar o objeto é o próprio nome deste, que é também o conteúdo gramatical estudado. Exemplos de nome/descritor: "personal care - el arreglo personal" e "por and para". Nesse viés, considera-se que o Más arriba não possui uma recuperabilidade minimamente considerável, sobretudo em função da falta de descritores, o que justifica o fato de este ser desconsiderado a partir deste momento na pesquisa. Quanto aos descritores pedagógicos, salientamos a presença de "Nível”, já sugerido por Leffa (2006a) na revisão de literatura. Este foi o descritor pedagógico mais utilizado, o que sugere que tanto o Repositório Acción E/LE quanto outros repositórios que almejem ser repositórios de OALs devam considerá-lo futuramente em suas listas de descritores.

Ainda sobre os descritores pedagógicos, contudo, lamentamos a falta do descritor “Objetivo(s)" em alguns dos repositórios. Lamentamos porque, para a concepção de OAL de Vetromille-Castro et. al. (2012), tal descritor pode ser considerado de suma importância. O objetivo pode ser considerado como o descritor que define se determinada atividade que se apresenta como um OA é um OAL, uma vez que pode ser a partir do objetivo do objeto que se nota o foco comunicativo, característica delimitadora de um OAL. Também é o objetivo que evidencia o viés pedagógico do OAL, entre outros aspectos de grande relevância. Apenas os sites Actividades FORMESPA e Aveteca de CVC apresentam o descritor "Objetivo(s)""

Sobre a média quantitativa do total de descritores, a somar aqueles que foram listados na tabela 2, podemos dizer que cada um dos repositórios conta com o seguinte número:

(1) Ejercicios de español para extranjeros - 5 descritores.

(2) Actividades FORMESPA - 8 descritores.

(3) ELO - Ensino de Línguas Online - 3 descritores.

(4) Lecturas paso a paso de CVC -5 descritores.

\footnotetext{
14 Outros sites, como o Lecturas paso a paso de CVC e o ELO - Ensino de Línguas Online, em determinadas atividades, deixam claro o objetivo destas. Contudo, não na forma de descritores, mas sim já no interior da atividade.
} 
(5) Aveteca de CVC - 8 descritores.

(6) Autoactividades de español em hlrnet.com -4 descritores.

A média harmônica de descritores empregados pelos repositórios é de mais ou menos 5 ou 6, valor bem menor que os 15 descritores propostos pelo site Dublin Core Metadata e os 13 descritores sugeridos por Clark e Rosset (2002). Esse número relativamente pequeno de descritores não precisa ser considerado negativo, tendo em vista que os repositórios avaliados utilizaram um número considerável de descritores pedagógicos. Em outras palavras, o número de descritores não precisa ser grande, amplo, como os propostos na revisão de literatura (CLARK; ROSSET, 2002, por exemplo). O número de descritores deve ser preciso. Se o número de descritores for suficiente para enfatizar a finalidade pedagógica do objeto, o número é satisfatório. Este é o caso dos dois repositórios oriundos do portal educacional Centro Virtual Cervantes (CVC). Tanto o Lecturas paso a paso quanto o Aveteca aplicam descritores pedagógicos.

Quanto ao acesso aos objetos, Leffa (2006a) explica que este pode ser realizado de modo estático ou dinâmico.

O acesso estático pode ser caracterizado como uma árvore invertida em que se parte do tronco para as folhas, de acordo com a taxonomia pré-estabelecida. É estático, porque, quando o usuário chega para iniciar a consulta, a estrutura dos tópicos e as relações entre eles já estão estabelecidas, cabendo, portanto, ao usuário adaptar-se e orientar-se por essa estrutura para chegar ao que deseja. O acesso dinâmico, por outro lado, estrutura-se a cada consulta do usuário. Tipicamente, há uma caixa de diálogo (“dialogue box"), onde o usuário digita o que deseja pesquisar, usando uma ou mais palavras, a partir da(s) qual(is) o sistema sugere, por algum critério de ordenação, uma lista de arquivos a serem consultados (LEFFA, 2006a, p.27).

Todos os repositórios avaliados dispõem de um acesso estático aos objetos, salvo o Autoactividades de español em hlrnet.com, que dispõe também de acesso dinâmico, por meio de uma ferramenta de busca. Tanto o acesso dinâmico quanto o acesso estático são possíveis neste site.

A maneira como os descritores estão expostos aos visitantes, contudo, deixou a desejar, pois nem todos os sites apresentam seus descritores de forma a facilitar o acesso ao objeto. Como no caso do site Ejercicios de español para extranjeros, em que os descritores são encontrados dispersados, separadamente, ao longo da navegação. Primeiro escolhe-se o tipo de exercício (Vocabulario, Escucha, Gramática) para ser encaminhado a uma página onde se pode escolher o tipo de atividade (Crucigrama, Juego de memória, etc.) e ainda vislumbra o nível 
(intermediário, básico, avançado...), tudo isso de forma bastante desorganizada. Não é, então, uma questão de falta de recuperabilidade em função da ausência de descritores, muito pelo contrário, pois este repositório em específico emprega descritores classificados como pedagógicos. É uma questão de falta de organização destes descritores, que se encontram relativamente mal distribuídos pelo site.

O site Autoactividades de español em hlrnet.com também pode ser incluído nesta crítica. Seus descritores não estão organizados, relacionados entre si, mas sim dispersos na página de formas distintas, como é possível ver na imagem a seguir.

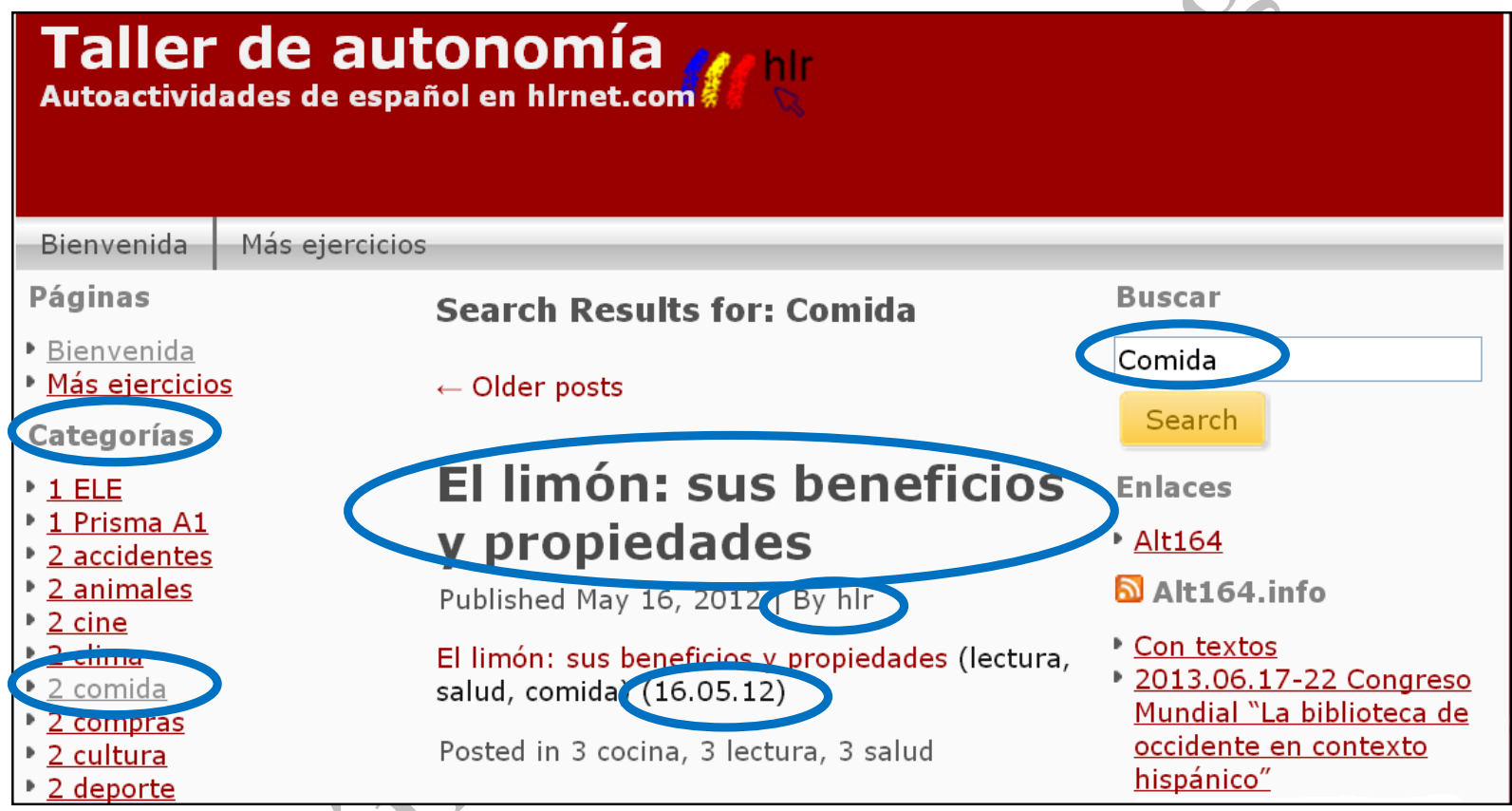

Imagem 2: Autoactividades de español em hlrnet.com ${ }^{15}$.

Como já comentado, felizmente o Autoactividades de español em hlrnet.com conta com a ferramenta de busca, de acesso dinâmico, o que aumenta seu nível de recuperabilidade.

Por outro lado, também podemos citar os exemplos dos sites que disponibilizam um tipo de tutorial quanto ao objeto a ser utilizado, que seria uma alternativa de melhoria para os sites que não organizam seus descritores em um espaço lógico. Os sites Actividades FORMESPA e Lecturaspaso a paso de CVC são modelos de repositórios com tutoriais com informações sobre o OA e seu uso para fins de aprendizagem de línguas. A boa notícia é que estes tutoriais, em

\footnotetext{
${ }^{15}$ Disponível em: http://hlrnet.com/taller/?s=Comida\&search=Search.
} 
sua maioria, são constituídos de informações pedagógicas, para auxilio tanto do professor quanto do aluno.

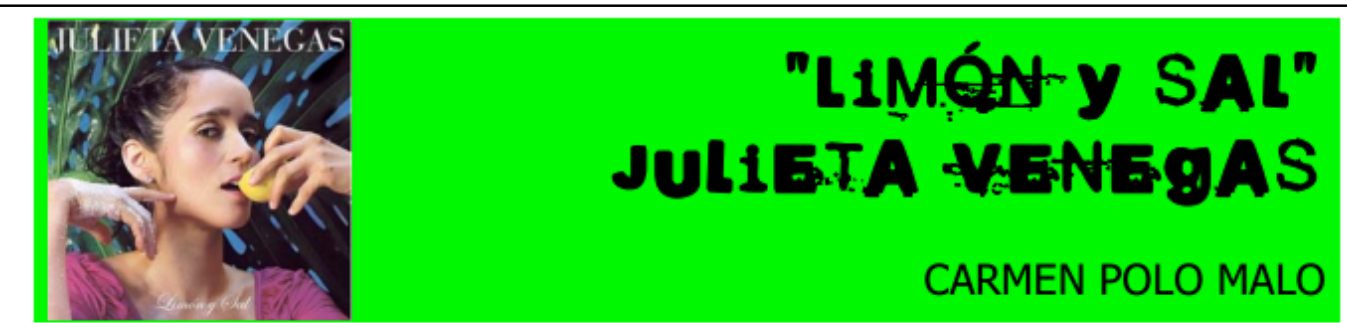

Nivel: A1

Destinatarios: jóvenes y adultos

\section{OBJETIVOS GENERALES}

Repaso de las destrezas: comprensión auditiva, comprensión lectora, expresión oral, expresión escrita.

\section{OBJETIVOS ESPECÍFICOS}

* Practicar las formas del presente de indicativo en verbos irregulares.

* Estimular la creatividad en la expresión escrita y oral.

* Hablar de relaciones personales.

* Repaso de vocabulario básico.

* Valoración del contexto para la comprensión.

* Contraste IR / VENIR.

\section{OBJETIVOS CULTURALES}

Ampliar los conocimientos de México a través de sus productos típicos y de su música.

\section{MATERIAL NECESARIO}

Imagem 3: Tutorial para uma das atividades do repositório Actividades FORMESPA ${ }^{16}$

O uso de tutoriais, ainda que seja um exemplo de boa organização de descritores (no sentido de estarem agrupados, bem distribuídos, relacionados harmonicamente entre si, em uma sequência lógica), não necessariamente é sinal de boa recuperabilidade. No caso dos dois sites citados, que apresentam tal tutorial, não são aplicados hiperlinks, o que não colabora com a navegação do site. São exemplos, então, de um bom modelo de organização de descritores, mas não de boa aplicação de recuperabilidade.

Além da presença do tutorial, alguns sites também disponibilizam junto a este uma breve descrição do objeto, o que pode ser considerado fator de melhoria da recuperabilidade, pelo menos no sentido de antecipar ao visitante do repositório algumas informações básicas sobre o

\footnotetext{
${ }^{16}$ Disponível em: http://formespa.rediris.es/canciones/pdfs/cpolo-venegas.pdf.
} 
OA. A seguir, apresentamos como exemplo a descrição da atividade da música Limón y Sal, da cantora Julieta Venegas, ilustrada na imagem anterior: "Ejercicios basados en la canción de esta cantante mexicana orientados a afianzar la conjugación irregular del presente de indicativo". Além do Actividades FORMESPA, o ELO também apresenta descrições básicas. O benefício no uso de descrições gerais e resumidas do objeto é justamente contemplar esses vários descritores que podem ser, por um lado, técnico e, por outro, pedagógico. "Tipos de atividades" ou "Conteúdo trabalhado", entre outros descritores, poderiam ser contemplados e resumidos em descrições básicas como: "WebQuest que trabalha os pontos turísticos da cidade de Madrid, na Espanha”, por exemplo.

Por fim, a última questão norteadora das análises nos repositórios trazia como tema o uso de descritores, tanto gerais quanto específicos, inéditos, ainda não vistos na revisão de literatura. Não foram encontrados descritores novos, mas foi notada a ausência de dois descritores que, na concepção dos autores da pesquisa, deveriam ser explorados em repositórios de OAs e OALs:

1) Acessibilidade. Já é de conhecimento geral que as TICs podem beneficiar significativamente Pessoas com Necessidades Educacionais Especiais (PNEEs) nos processos de ensino-aprendizagem. Isso é bastante difundido inclusive por alguns autores que debatem o uso de OAs para pessoas com deficiência visual ou sujeitos surdos, a modo de exemplo ${ }^{17}$. Com isso, torna-se evidente a importância de um descritor que trate de apontar se determinado OA ou OAL cabe para determinadas PNEEs.

2) Variedade linguística. Como acréscimo aos descritores de línguas, um descritor que aparenta ser importante para a descrição de OAs/OALs específicos de E/LE, seria a variação da língua utilizada ou, talvez, a origem do referido objeto. No caso, a finalidade de tal descritor seria indicar se tal recurso contempla determinada variante ou a explora, como é o caso do voseo, o uso do pronome vos em países como Argentina e Uruguai. Também estaria incluso neste descritor a questão de o objeto haver sido produzido para aprendizes de diferentes línguas maternas. Este parece ser um descritor necessário se considerarmos as especificidades do processo de aprendizagem de E/LE para as diferentes línguas maternas dos aprendizes. Por exemplo, se um OAL tiver como público-alvo aprendizes ingleses de língua espanhola, o

\footnotetext{
17 Destacamos os seguintes pesquisadores: (1) Elton Vergara Nunes, doutorando em Engenharia e Gestão do Conhecimento, pela Universidade Federal de Santa Catarina, e autor de pesquisas sobre TICs acessíveis a pessoas com Deficiência Visual (DV) e construção de OAs acessíveis. (2) Nairana Hoffmann Sedrez, mestranda em Letras, pela Universidade Católica de Pelotas, e autora de pesquisas sobre OALs na aplicação a alunos ouvintes e surdos.
} 
professor de espanhol para brasileiros deverá ser informado disso e usar tal objeto se assim julgar importante, necessário.

\section{Considerações finais}

O impacto esperado pelos propositores e pesquisadores dos OALs considera, sobretudo, a facilitação tanto do processo de ensino e aprendizagem quanto do trabalho docente, principalmente quanto à otimização do tempo. Um OAL que possa ser, antes de reusado e adaptado, facilmente localizado, identificado e recuperado, justifica a importância da característica recuperabilidade.

Sob essa perspectiva, apresentamos o seguinte problema hipotético: um professor de E/LE, ao procurar determinado OAL, com características específicas e que possa ser usado para dado fim, acaba se deparando com o "infinito ao seu redor" que é a Internet hoje em dia. Mesmo ao buscar em um repositório digital, este professor não consegue localizar o OAL desejado, possivelmente porque há uma evidente baixa (ou total ausência) de recuperabilidade em tal site. Na situação ilustrada, o longo tempo que o docente empregaria para encontrar um OAL que se enquadre em suas pretensões pedagógicas colocaria em xeque a importância do próprio objeto. Afinal, se tanto tempo é consumido para encontrar - recuperar - um OAL, valeria muito mais a pena para o professor consumir esse mesmo tempo produzindo seu próprio objeto, à sua própria vontade e necessidade. Eis aí a importância da recuperabilidade e o papel dos descritores em repositórios digitais.

Diferentemente do que prevíamos no início desta pesquisa, encontramos uma quantidade notável de descritores pedagógicos, embora estes não estejam organizados e bem explorados nos repositórios analisados. Não concluímos, portanto, que há uma preferência por descritores técnicos ao uso de descritores pedagógicos, como imaginávamos anteriormente, o que é uma boa notícia. Evidentemente, alguns descritores pedagógicos ainda precisam ser incorporados e melhor aplicados, como é o caso do descritor "Objetivo(s)", por exemplo. Ainda assim, os resultados podem ser mais positivos do que poderíamos esperar no início da investigação, pois descritores pedagógicos estão sendo aplicados.

Concluímos, isso sim, que os repositórios precisam melhorar seu nível de recuperabilidade no que diz respeito à forma de organização e disposição de seus descritores em suas páginas. Mesmo a presença de muitos descritores pode ser prejudicada se estes não 
estão organizados, dispostos de maneira clara ao visitante, atuando por meio de combinação de informações, etc.

Este problema pode ser solucionado justamente a partir de uma análise comparativa de repositórios, em que o melhor de cada repositório pode servir como exemplo para o aprimoramento da recuperabilidade de um site que armazene OAs/OALs. Ao considerarmos que a forma como estão dispostos os descritores presentes nos tutoriais do Actividades FORMESPA e que o acesso estático do repositório ELO, por exemplo, são ideais, podemos entender que a combinação de ambos é um bom exemplo de como um repositório digital de OALs deveria ser. Ao considerarmos que as duas possibilidades de acesso áos objetos dinâmico e estático - do Autoactividades de español em hlrnet.com é o mais indicado, podemos entender que um repositório deva ofertar ambas as alternativas a seus visitantes. E assim por diante.

Além de "Nome", descritores pedagógicos como "Nível" e “Objetivo", entre outros, são essenciais, pelo que podemos ver nos repositórios, da mesma maneira que certos descritores ainda não experimentados, como "Acessibilidade". Apenas o uso de tais descritores, contudo, não é sinal de boa recuperabilidade, ou de recuperabilidade pedagógica, pois a desorganização da distribuição dos descritores no site pode não ajudar o acesso ao recurso visado.

Esperamos com os resultados desta pesquisa que não apenas o Repositório Acción E/LE, que futuramente armazenará OALs sempre visando um alto nível de recuperabilidade, tenha se beneficiado com os resultados obtidos. Esperamos que todos os repositórios, seja de OAs, de OALs ou de TICs em geral, possam aprimorar cada vez mais seu nível de facilitação de acesso aos recursos que armazenam em seu interior.

\section{Referências}

CANALE, M.; SWAIN, M. Theoretical Bases of Communicative Approaches to Second Language Teaching and Testing. Applied Linguistics, vol. 1, p.1-47, 1980.

CASTRO, P. Z.; SEDREZ, N. H. A reusabilidade do Objeto de Aprendizagem de Línguas em seus dois vieses. In: XX CONGRESSO DE INICIAÇÃO CIENTÍFICA. Anais. Pelotas, Rio Grande do Sul, 2011.

CLARK, R.; ROSSETT, A. Learning Solutions - Learning Objects: Behind the Buzz. Chief Learning Officer Magazine, 2002. Disponível em http://clomedia.com/articles/view/learning_solutions_learning_objects_behind the buzz/6. Acesso em 11 junho 2006. 
COSTA, A. R.; FIALHO, V. R. Objetos de Aprendizagem para o ensino de Espanhol como Língua Estrangeira: definição e perspectiva teórica. In: XII SEMINÁRIO INTERNACIONAL IN LETRAS. Língua e Literatura na (pós-)modernidade. Anais. Santa Maria, Rio Grande do Sul. 2012.

ELO. Ensino de Línguas Online. Disponível em http://www.leffa.pro.br/elo/. Acesso em 29 julho 2012 .

GALLO, P.; PINTO, M. das G. Professor, esse é o objeto virtual de aprendizagem. Revista Tecnologias na Educação, vol. 2, n. 1, p.1-12, 2010.

GAMA, C. L. G. da. Método de construção de Objetos de Aprendizagem com aplicação em métodos numéricos. 2007. 210f. Tese (Doutoradoem Métodos Numéricos em Engenharia) - Universidade Federal do Paraná, Curitiba, Paraná. 2007.

GARCIA, S. C.; LEFFA, V. J. Percepção e uso da informática por um grupo de professores da área de Letras. Revista Contrapontos - Eletrônica, vol. 10, n. 3, p. 327-337, set./dez. 2010.

GARCIA, S. C. Objetos de aprendizagem como artefatos mediadores da construção do conhecimento: um estudo com base na Epistemologia Histórico-Cultural. 2011. 236f. Tese (Doutorado em Letras) - Universidade Católica de Pelotas, Pelotas, Rio Grande do Sul, 2011.

LEFFA, V. J. Nem tudo que balança cai: Objetos de aprendizagem no ensino de línguas. Polifonia. Cuiabá, vol. 12, n. 2, p. 15-45, 2006 a.

. Uma ferramenta de autoria para o professor. O que é e o que faz. Letras de Hoje. vol. 41, n. 144, p. 189-214, 2006 b.

LTSC. Learning Technology Standards Committee. Disponível em http://ltsc.ieee.org/wg12/. Acesso em 10 agosto 2012.

McGREAL, R. Learning objects: A practical definition. International Journal of Instructional Technology and Distance Learning (IJITDL), vol.9, n. 1, 2004. Disponível em http://www.itdl.org/journal/sep_04/article02.htm. Acesso em 10 maio 2012.

SCHWARZELMÜLLER, A. F.; ORNELLAS, B. Os Objetos Digitais e suas Utilizações no Processo de Ensino-Aprendizagem. In: 1ERA CONFERENCIA LATINOAMERICANA DE OBJETOS DE APRENDIZAJE. Anais. Guayaquil, Equador, 2006.

SILVA, J. T.; FAGUNDES, L. da C.; BASSO, M. V. Metodologia de apoio ao processo de aprendizagem via autoria de objetos de aprendizagem por alunos. Novas Tecnologias na Educação, vol. 6, n. 1, 2008.

SOUTH, J.; MONSON, D. A University-wide System for Creating, Capturing, and Delivering Learning Objects. Disponível em http://reusability.org/read/chapters/south.doc. Acesso em 12 agosto de 2012. 
TAVARES, A. C. O papel dos objetos de aprendizagem no ensino de línguas: uma análise em cursos on-line de espanhol como língua estrangeira. 2007. 113f. Dissertação (Mestrado em Letras) - Universidade Católica de Pelotas, Pelotas, Rio Grande do Sul, 2007.

TAROUCO, L. M. R.; FABRE, M. C.; TAMUSIUNAS, F. R. 2003. Reusabilidade de objetos educacionais. Novas Tecnologias na Educação, vol. 1, n. 1, 2003.

VETROMILlE-CASTRO, R.; MOOR, A. M.; DUARTE, G. B.; SEDREZ, N. H. Objetos de Aprendizagem de Línguas: uma proposta. In: VETROMILLE-CASTRO, R.; HEEMANN, C.; FIALHO, V. R. (Org.). Aprendizagem de Línguas - a Presença na Ausência: CALL, Atividade e Complexidade. Pelotas: Educat. 2012. p.241-256.

WILEY, D. A. Connecting learning objects to instructional design theory: A definition, a metaphor, and a taxonomy. In: WILEY, D. A. (Org.). The instructional Use of Learning Objects. Online Version. 2000.

Artigo recebido em: 28.02.2013

Artigo aprovado em: 12.04.2013 